\title{
Vacuum tube window technology for highly insulating building fabric: An experimental and numerical investigation
}

\author{
Erdem Cuce`, Saffa B Riffat \\ Department of Architecture and Built Environment, Faculty of Engineering, University of \\ Nottingham, University Park, NG7 2RD Nottingham, UK \\ *Corresponding author email: laxec5@nottingham.ac.uk; Tel: +44 (0) 1159514882
}

\begin{abstract}
A novel vacuum tube window technology is introduced, and its thermal performance efficiency is both experimentally and numerically investigated. Heat transfer inside the window is modeled via a reliable commercial computational fluid dynamics software ANSYS FLUENT. For various vacuum tube diameters $(28,50,70$ and $80 \mathrm{~mm})$, an excellent accordance is observed between experimental and numerical data. The U-value of vacuum tube window is determined for different values of design parameters such as pane thickness, tube thickness, tube diameter and argon gap. As a consequence of thermal performance characteristics, cost, lightness and aesthetic issues, the optimum vacuum tube diameter is found to be $60 \mathrm{~mm}$. It is concluded from the results that the vacuum tube window technology has a U-value below $0.40 \mathrm{~W} / \mathrm{m}^{2} \mathrm{~K}$, which corresponds to five times better thermal insulation performance than commercial argon filled double glazed windows with low-e.
\end{abstract}

Keywords: Low-carbon buildings, energy-efficient glazing, vacuum tube window, U-value

\section{Introduction}

Global energy consumption rapidly grows day to day as a consequence of the remarkable growing trend of world population, increasing demand for transportation and building services, and rising comfort levels with technology, bringing with it serious environmental impacts such as ozone layer depletion, global warming and climate change [1]. Today, there is a global consensus among scientists that the existing energy resources will be exhausted in the near future [2]. Both this reality and growing significance of environmental issues prompt developed and developing countries to 
recheck their energy policies regarding energy production and consumption [3,4]. Especially following the decades of 1973 oil crisis, numerous attempts are made to alleviate the domination of fossil fuels in global energy consumption by focusing the world's attention on renewables. However, recent reports indicate that the renewable energy sources currently can meet only $14 \%$ of the global energy demand [5], which is not sufficient for a decisive measure. Therefore, energy minimization and its efficient use at global scale are crucially required.

Recent research of International Energy Agency on global sectoral energy consumption clearly reveals that domestic sector plays a role on global energy use, and hence greenhouse gas emissions [6]. Kolokotsa et al. [7] report that the energy consumption in buildings accounts for $40 \%$ of the energy used worldwide. In another work, Zhao and Magoules [8] note that the buildings in Europe are responsible for $40 \%$ of total energy consumption and $36 \%$ of total $\mathrm{CO}_{2}$ emission. Sadineni et al. [9] emphasize that the situation is almost the same in the USA. About 39\% of the total primary energy in the USA is consumed by buildings. These dramatic scenarios can be attributed to the poor thermal insulation characteristics of existing building fabric technologies. In this respect, building sector is considered one of the most promising ways to be able to reduce primary energy consumption, and thus to mitigate greenhouse gas emissions [10].

Windows are indispensable components of building envelope which provide vision, air ventilation, passive solar gain, day-lighting and the opportunity to leave the building in extreme situations. On the other hand, they play a dramatic role in heating and cooling loads of buildings in winter and summer, respectively due to their notably higher U-values compared to the other components of buildings as illustrated in Figure 1. Windows are responsible for about $60 \%$ of the total energy loss of a building [11]. Hence, developing windows with low thermal transmittance can substantially contribute in reducing energy costs of buildings, and can provide large energy savings.

Currently, the window market in the world is predominated by double glazing technology, and a great majority of houses that are built now have double glazing fitted as standard. However, windows are still responsible for almost half of heat loss from building envelope [12]. The ability to construct highly efficient buildings will only be achieved if measures are taken to decrease fabric Uvalues and incorporate efficient window technologies. Windows however do not comprise merely of the glazing component but also the frame, which has aspects of both heat transmission and air tightness to consider. In this regard, it is important to identify appropriate technologies to manufacture energy efficient windows, which will also improve the visual and thermal comfort of the occupants.

This study aims at introducing an extraordinary window technology called vacuum tube window for low-carbon buildings. Several attempts are made in literature to improve overall performance parameters of vacuum glazing. Eames [17] presents an overview of vacuum glazing technology and 
outlines the future prospects through the latest reports on commercial products. Zhao et al. [18] develop a method to prepare transparent supporting spacers for vacuum glazing. Transparent glass spacers between the glass sheets are found to be very efficient to improve appearance and light transmittance. Schultz and Jensen [19] combine monolithic silica aerogel and vacuum concept into a single glazing and investigate the thermal insulation performance. Their results indicate that an evacuated aerogel glazing with $20 \mathrm{~mm}$ glass distance can yield a U-value below $0.5 \mathrm{~W} / \mathrm{m}^{2} \mathrm{~K}$. It is concluded from the previous works on vacuum glazing that the fabrication cost is still very high and attractive U-values for low/zero carbon buildings are very difficult to achieve. Therefore in this research, a unique design of vacuum glazing is introduced. This novel window is based on vacuum phenomenon and provides highly thermal insulating ability via its thermally optimized design. Within the scope of this research, experimental and numerical investigation of vacuum tube window are presented to justify its efficiency, reliability, practicality and sustainability for both retrofitting of existing buildings and new-build applications. For the tube diameters of 28 and $70 \mathrm{~mm}$, the average $\mathrm{U}$-value of the window is analyzed both experimentally and numerically, and an excellent agreement between the results is achieved. Similar accordance is observed for the tube diameters of 50 and 80 $\mathrm{mm}$ for the readers' interest.

\section{Vacuum tube window technology}

Vacuum tube window technology can be summarized as the combination of a particular amount of evacuated glass tubes at optimized dimensions, and integration of them into a double glazed frame as illustrated in Figure 2. The evacuated tubes at a particular vacuum pressure are fixed between two glass window panes and for the external connection between vacuum tubes, an insulating adhesive is utilized. However, evacuated tubes can also be installed separately to eliminate potential thermal bridges through the adhesive. The surrounding enclosure between the vacuum tubes and the window panes is filled by argon as inert gas.

It is well known in literature that heat transfer through conduction and convection are eliminated in vacuum media, thus heat is only transferred by thermal radiation. On the other hand, thermal radiation is usually neglected in heat transfer analyses when the temperature difference between the surfaces is low. This phenomenon is the underlying reason of the vacuum tube window technology. Following the elimination of conduction, convection and radiation inside the evacuated tubes, natural convection of surrounding stream is minimized by selecting a proper inert gas. Among the existing types of inert gases, argon has some specific advantages let it to be used in vacuum tube window. argon is the third most common gas in the Earth's atmosphere, at 0.93\% (9,300 ppm), making it approximately 23.8 times as abundant as the next most common atmospheric gas, carbon dioxide (390 ppm), and more than 500 times as abundant as the next most common noble gas, neon [13]. 
argon is produced industrially by the fractional distillation of liquid air. Thermal conductivity of argon at room temperature is quite low compared to other inert gases, which is around $0.016 \mathrm{~W} / \mathrm{mK}$. As a consequence of its good thermal resistance, it is used between the panes of the vacuum tube window to minimize the heat loss through convection.

\section{Experimental analysis}

Thermal insulation performance of vacuum tube window technology is experimentally investigated through two different samples with different tube diameters. A standardized co-heating test methodology is applied to the samples as shown in Figure 3. The first sample tested in the environmental chamber has a tube diameter of $28 \mathrm{~mm}$. Although this is not the optimized geometry for vacuum tube window, it is still tested in order to demonstrate the impact of thermal bridges on the U-value at smaller tube diameters and how this undesired output is elucidated at greater tube diameters like $70 \mathrm{~mm}$. In addition to that, the selected tube diameter of $28 \mathrm{~mm}$ equals the entire thickness of the most common double glazed window structure among the existing commercial products $(4 \mathrm{~mm}$ glass pane $+20 \mathrm{~mm}$ air gap $+4 \mathrm{~mm}$ glass pane $)$. In this respect, relevant comparisons can also be made. The second window sample has a tube diameter of $70 \mathrm{~mm}$ as a consequence of the optimized data through the computational fluid dynamics (CFD) simulations. The fabrication of vacuum tube window samples is performed in Vale Window Company Ltd., which is located in Mansfield, UK.

\section{Numerical analysis}

Following the experimental investigation of vacuum tube window samples in the environmental chamber, a CFD based research is conducted for numerical modeling of heat transfer inside the vacuum tube window. A well-known CFD software ANSYS FLUENT [14] is utilized in this work. GAMBIT is used for the mesh generation. 2D CFD model is constructed with triangular mesh. Mesh independent solution is achieved for each case before initializing the analyses. PRESTO discretization is preferred for an accurate and reliable assessment. For the accuracy verification of the methodology, the CFD results are compared with those of a previously published theoretical work conducted by Trinuruk et al. [15], and an excellent agreement between the results compared is achieved as shown in Figure 4. The cross-sectional view of the vacuum tube window utilized in CFD analyses is illustrated in Figure 5. The U-value of the vacuum tube window is theoretically investigated for different values of design parameters such as tube diameter (D), tube thickness $(\alpha)$, $\operatorname{argon}$ thickness $(\beta)$ and pane thickness $(\delta)$. Through the results obtained, optimum design parameters are discussed in terms of thermal insulation performance, cost, lightness and aesthetic issues. 


\section{Results and Discussion}

The research conducted in this paper covers experimental and numerical investigation of vacuum tube window technology. In this respect, the results are split into two categories as experimental and CFD results for an easier understanding and comparison.

\subsection{Results from environmental chamber tests}

The experimental performance investigation of vacuum tube window technology is carried out for two samples with different tube diameters. The first sample has a tube diameter of $28 \mathrm{~mm}$ in order to demonstrate the dominant influence of thermal bridges on the U-value for the entire window thicknesses below $40 \mathrm{~mm}$. The second sample has a tube diameter of $70 \mathrm{~mm}$ as a consequence of the preliminary numerical data from CFD research representing one of the optimum design configurations. The samples are installed at different faces of hot box unit and tested under the same operating conditions provided in the environmental chamber. The temperature inside the hot box unit is adjusted to $20{ }^{\circ} \mathrm{C}$ via a temperature controlled heating system, while the ambient temperature is kept at $5{ }^{\circ} \mathrm{C}$ through the control unit of environmental chamber. The tests are started following the assurance of steady-state conditions in both hot box unit and environmental chamber as shown in Figure 6.

To be able to determine the U-value of each sample, internal and external glazing temperatures and heat flux values are measured as time-dependent through three different locations on the samples. The locations are selected from the diagonal line of each sample covering the centre point. Three independent tests are carried out to check the consistency of the experiments. The results for the first vacuum tube window sample with the tube diameter of $28 \mathrm{~mm}$ are illustrated in Figure 7 . For the locations of top corner, centre and bottom corner, the overall U-values are determined to be $2.11,2.22$ and $2.70 \mathrm{~W} / \mathrm{m}^{2} \mathrm{~K}$, respectively. The $\mathrm{U}$-value of the vacuum tube window is highly dependent on the tube diameter. Especially for tube diameters below $30 \mathrm{~mm}$, thermal bridging effects predominate inside the window, which result in poor thermal performance. For the aforementioned tube diameter, the numerical $\mathrm{U}$-value is found to be about $2.20 \mathrm{~W} / \mathrm{m}^{2} \mathrm{~K}$ through CFD analysis, which is in excellent agreement with the experimental results. The CFD results are comprehensively presented in the next section.

Following the preliminary CFD analysis of vacuum tube window which aims at determining the optimum design parameters for the best thermal insulation performance, the second sample is fabricated with a tube diameter of $70 \mathrm{~mm}$, and subjected to the same experimental methodology. On the contrary to the thermal performance characteristics of vacuum tube window at low tube diameters, the second sample provides a very promising range of $U$-value as shown in Figure 8. The average experimental $\mathrm{U}$-value of the vacuum tube window with the tube diameter of $70 \mathrm{~mm}$ is 
found to be $0.54 \mathrm{~W} / \mathrm{m}^{2} \mathrm{~K}$. As it is clear from the CFD results presented in the next section, the expected U-value at $70 \mathrm{~mm}$ tube diameter is below $0.40 \mathrm{~W} / \mathrm{m}^{2} \mathrm{~K}$. This small deviation between experimental and numerical results is totally a consequence of the impact of tube thickness. The CFD analysis considers the tube thickness to be $1 \mathrm{~mm}$ as the most appropriate design configuration. However, the tube thickness of the sample is $2 \mathrm{~mm}$ due to some challenges in fabrication and evacuation, which triggers the thermal bridges inside the vacuum tube window and deteriorates the thermal performance. Therefore, intensive efforts are currently underway to develop novel highly insulating glass-based materials to be able to achieve the desired U-value range.

\subsection{Results from CFD analyses}

The dissemination of the numerical results starts with the contours of static temperature plotted with respect to changes in tube diameter. Figure 9 and 10 clearly show that the conductive effects are dominant in heat transfer inside the vacuum tube window. However, it is understood that the convective effects become significant for the higher values of $\alpha, \beta$ and $\delta$. Parametric study is carried out for the tube diameter of 70 and $80 \mathrm{~mm}$. Effects of the thickness of argon gap on the heat loss and the U-value are given in Figure 11. It is found from the results that the thickness of argon gap has a significant impact on heat loss from the vacuum tube window. For the constant tube and pane thickness, the total amount of heat loss rises exponentially with increasing argon gap whereas it nearly remains constant for the argon thickness up to $2 \mathrm{~mm}$. Similar heat transfer characteristics are observed for the tube diameter of 70 and $80 \mathrm{~mm}$.

For each tube diameter, similar thermal insulation characteristics are observed as illustrated in Figure 11. For argon thickness of 1 and $2 \mathrm{~mm}$, the U-value is found to be around $0.40 \mathrm{~W} / \mathrm{m}^{2} \mathrm{~K}$ which is very noticeable. On the other hand, the $\mathrm{U}$-value exceeds $1.00 \mathrm{~W} / \mathrm{m}^{2} \mathrm{~K}$ while $\beta$ increases 2 to $3 \mathrm{~mm}$. The U-value is found to be greater than $2 \mathrm{~W} / \mathrm{m}^{2} \mathrm{~K}$ if $\beta$ exceeds $5 \mathrm{~mm}$. Secondly, the effects of the tube thickness on heat loss and the U-value are investigated for constant pane thickness and argon gap as illustrated in Figure 12. The results indicate that both the total heat loss and the U-value of the vacuum tube window exponentially increase with the tube thickness. For $\mathrm{D}=80 \mathrm{~mm}$, the U-value of the vacuum tube window is determined to be around $0.40 \mathrm{~W} / \mathrm{m}^{2} \mathrm{~K}$ for $\alpha=2 \mathrm{~mm}$ whereas it is about $0.80 \mathrm{~W} / \mathrm{m}^{2} \mathrm{~K}$ for $\alpha=5 \mathrm{~mm}$. Similarly, U-value is found to be 0.50 and $1.00 \mathrm{~W} / \mathrm{m}^{2} \mathrm{~K}$ for $\alpha=2$ and 5 $\mathrm{mm}$, respectively if the tube diameter is taken to be $70 \mathrm{~mm}$.

Pane thickness $(\delta)$ is also investigated in the study as an effective parameter on the heat loss and the U-value of vacuum tube window. Since the increment in $\delta$ contributes to the increase of the thermal resistance, the total heat loss from vacuum tube window decreases linearly with increasing pane thickness as shown in Figure 13. However, the magnitude of this change in heat loss can be considered negligible since $\delta$ varies only from 1 to $5 \mathrm{~mm}$. It is concluded from the results that the 
pane thickness has a negligible impact on the total heat loss and the U-value in comparison with the tube thickness and argon gap. Tube diameter (D) is a crucial parameter for the novel vacuum tube window. Thermal characteristics are highly dependent on tube diameter. Optimization of this parameter is therefore significant since greater values of D correspond to heavier constructions in buildings. In this regard, effects of tube diameter on average surface temperature, total heat transfer surface area, total heat loss and U-value are determined as given in Figure 14. The total heat transfer surface area increases linearly with increasing tube diameter as expected. The average cold surface temperature of the vacuum tube window exponentially decreases with tube diameter. The heat loss and the U-value are highly dependent on the tube diameter. The U-value is found to be around 0.30 and $2.00 \mathrm{~W} / \mathrm{m}^{2} \mathrm{~K}$ for $\mathrm{D}=80$ and $20 \mathrm{~mm}$, respectively. There is not a remarkable difference between the $\mathrm{U}$-values for $\mathrm{D}=60,70$ and $80 \mathrm{~mm}$. From this point of view, it can be concluded that $60 \mathrm{~mm}$ is the optimum value for tube diameter which results a $U$-value around $0.40 \mathrm{~W} / \mathrm{m}^{2} \mathrm{~K}$.

For readers' interest, some tests are carried out for the tube diameters of 50 and $80 \mathrm{~mm}$ in order to demonstrate the reliability of the CFD model. As it is seen in Figure 15, the numerical results are in good accordance with those of environmental chamber tests. The influence of thermal bridges on the thermal insulation performance of vacuum tube window decreases with increasing tube diameter as expected. This output can be attributed to reduction in the ratio of glass volume to the combined volume of vacuum and inert gas. Thermal radiation is almost negligible in vacuum tube window design due to the low temperature difference between indoor and outdoor. Natural convection is also controlled through unique configuration of vacuum tube window and proper selection of inert gas resulting to remarkably low overall U-values. In further works, pure theoretical heat transfer models $[20,21]$ can be developed for demonstrating the efficiency and the reliability of vacuum tube glazing technology.

\section{Conclusions}

In this paper, a novel window technology called vacuum tube window is introduced to remarkably mitigate energy consumption of buildings. Recent reports from manufacturers indicate that the windows are still responsible for a significant amount of energy loss from building envelope due to their poor thermal insulation performance characteristics as shown in Table 1 [16]. However, the novel vacuum tube window technology provides an extraordinary thermal resistance as verified by experimental and numerical analyses, resulting large energy savings in building sector. Since the fabrication of vacuum tube window technology is also simple and cost-effective, it is expected to dominate the fenestration industry in the near future.

\section{Acknowledgements}


Authors gratefully acknowledge the financial support of Department of Energy \& Climate Change (DECC) for this work through DECC-HPVTW Project.

\section{References}

[1] Lombard LP, Ortiz J, Pout C. A review on building energy consumption information. Energy and Buildings 2008; 40: 394-8.

[2] Riffat SB, Cuce E. A review on hybrid photovoltaic/thermal collectors and systems. International Journal of Low-Carbon Technologies 2011; 6(3): 212-41.

[3] Wang R, Liu W, Xiao L, Liu J, Kao W. Path towards achieving of China's 2020 carbon emission reduction target - A discussion of low-carbon energy policies at province level. Energy Policy 2011; 39: 2740-7.

[4] Cuce E, Cuce PM, Wood CJ, Riffat SB. Optimizing insulation thickness and analysing environmental impacts of aerogel-based thermal superinsulation in buildings. Energy and Buildings 2014; 77: 28-39.

[5] Cuce E, Cuce PM, Wood CJ, Riffat SB. Toward aerogel based thermal superinsulation in buildings: A comprehensive review. Renewable and Sustainable Energy Reviews 2014; 34: 273-99.

[6] International Energy Agency. Technology Roadmap - Energy efficient building envelopes, December 2013.

[7] Kolokotsa D, Rovas D, Kosmatopoulos E, Kalaitzakis K. A roadmap towards intelligent net zero- and positive-energy buildings. Solar Energy 2011; 85: 3067-84.

[8] Zhao H, Magoules F. A review on the prediction of building energy consumption. Renewable and Sustainable Energy Reviews 2012; 16: 3586-92.

[9] Sadineni SB, Madala S, Boehm RF. Passive building energy savings: A review of building envelope components. Renewable and Sustainable Energy Reviews 2011; 15: 3617-31.

[10] Janda KB, Busch JF. Worldwide status of energy standards for buildings. Energy 1994; 19(1): $27-44$.

[11] Jelle BP, Hynd A, Gustavsen A, Arasteh D, Goudey H, Hart R. Fenestration of today and tomorrow: A state-of-the-art review and future research opportunities. Solar Energy Materials and Solar Cells 2012; 96: 1-28.

[12] Cuce E, Young CH, Riffat SB. Performance investigation of heat insulation solar glass for low-carbon buildings. Energy Conversion and Management 2014; 88: 834-41.

[13] Covai Air Products. Liquid Argon. http://covaiair.co.in/liquidargon.html. (Last access was on 01.10.2014).

[14] FLUENT (2005), Fluent Inc. 
[15] Trinuruk P, Sorapipatana C, Chenvidhya D. Estimating operating cell temperature of BIPV modules in Thailand. Renewable Energy 2009; 34: 2515-23.

[16] Understanding the Government's data on U-values. http://www.pilkington.com. (Last access is on 31.07 .2014$)$.

[17] Eames PC. Vacuum glazing: Current performance and future prospects. Vacuum 2008; 82: $717-22$.

[18] Zhao JY, Luo SY, Zhang XL, Xu WC. Preparation of a transparent supporting spacer array for vacuum glazing. Vacuum 2013; 93: 60-4.

[19] Schultz JM, Jensen K. Evacuated aerogel glazings. Vacuum 2008; 82: 723-9.

[20] Hajmohammadi MR, Rahmani M, Campo A, Shariatzadeh OJ. Optimal design of unequal heat flux elements for optimized heat transfer inside a rectangular duct. Energy 2014; 68: 609-16.

[21] Hajmohammadi MR, Shariatzadeh OJ, Moulod M, Nourazar SS. Phi and Psi shaped conductive routes for improved cooling in a heat generating piece. International Journal of Thermal Sciences 2014; 77: 66-74. 
Table 1. U-values of commercial glazing products

\begin{tabular}{lc} 
U-value $\left(\mathrm{W} / \mathrm{m}^{2} \mathrm{~K}\right)$ & Pilkington [16] \\
\hline Air filled double glazed window & 2.70 \\
Air filled double glazed window with low-e & 2.00 \\
Argon filled double glazed window with low-e & 1.80 \\
& \\
U-value $\left(\mathrm{W} / \mathrm{m}^{2} \mathrm{~K}\right)$ & This work \\
\hline Vacuum tube window & 0.40
\end{tabular}




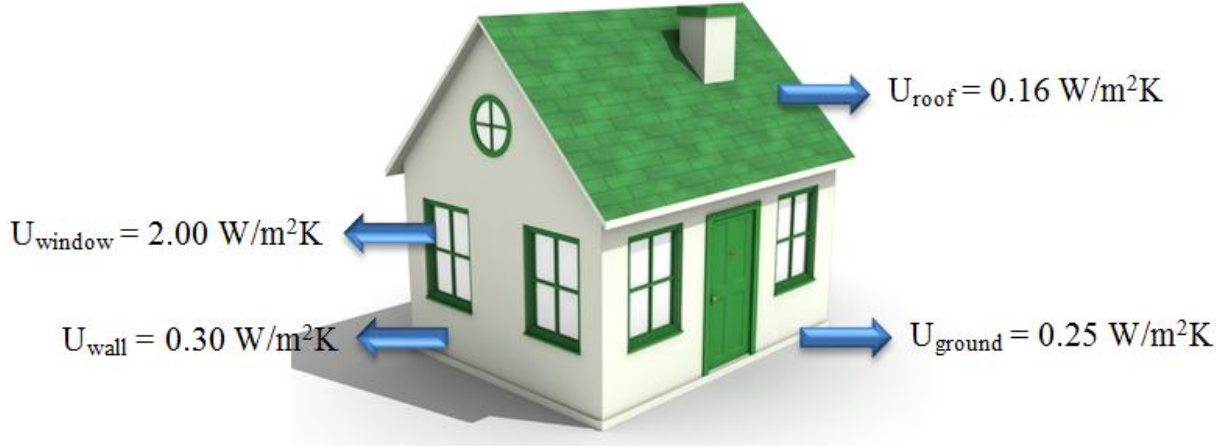

Figure 1. Typical U-values of building elements. 

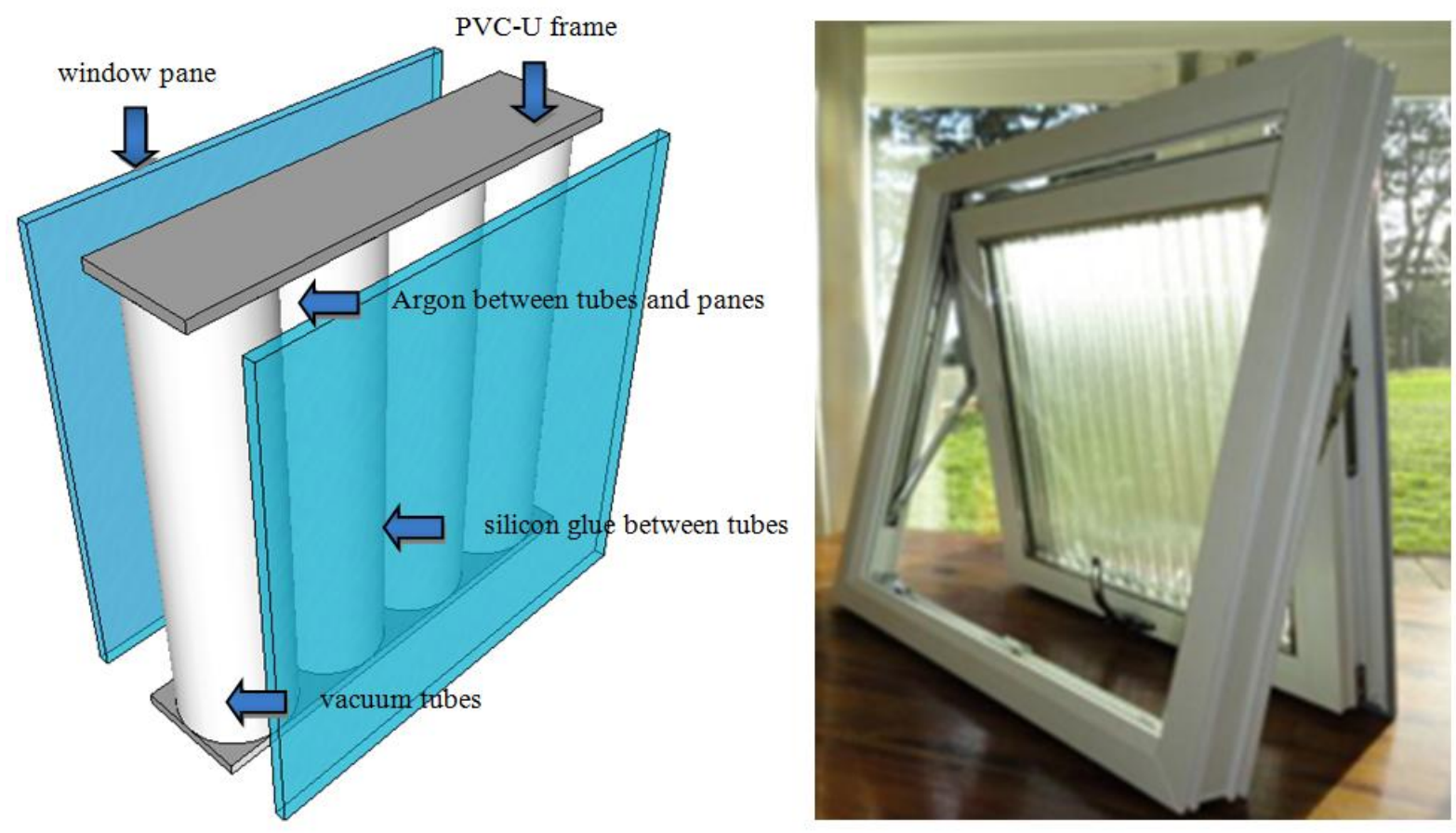

Figure 2. Schematic of the vacuum tube window (on the left) and the sample developed (on the right). 


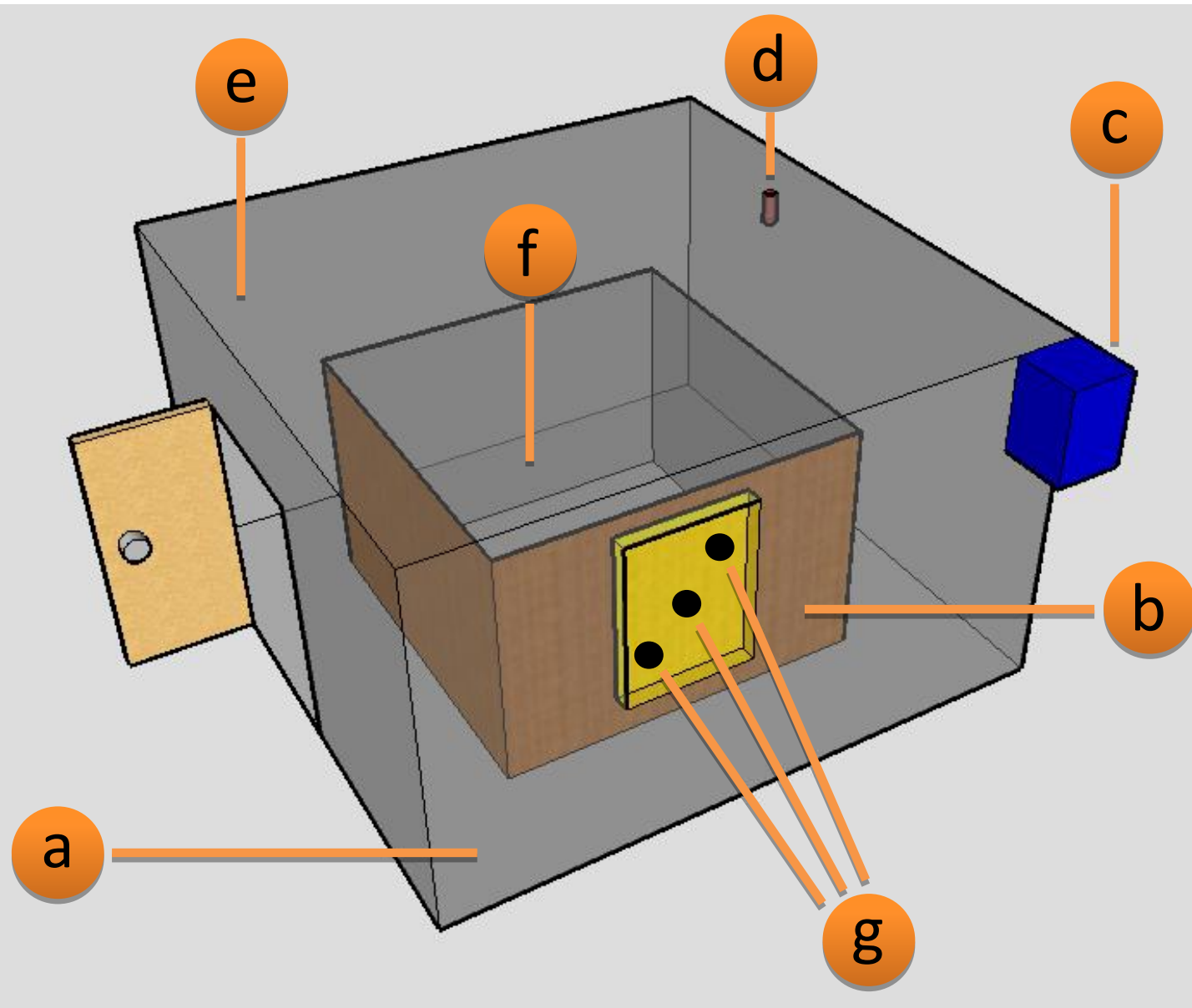

Figure 3. Co-heating test methodology performed in the environmental chamber: a) environmental chamber, b) hot box unit, c) control system, d) temperature and humidity control of environmental chamber, e) $5{ }^{\circ} \mathrm{C}$ chamber temperature, f) $20{ }^{\circ} \mathrm{C}$ hot box temperature and g) heat flux and temperature measurements through three different locations on the vacuum tube window sample. 

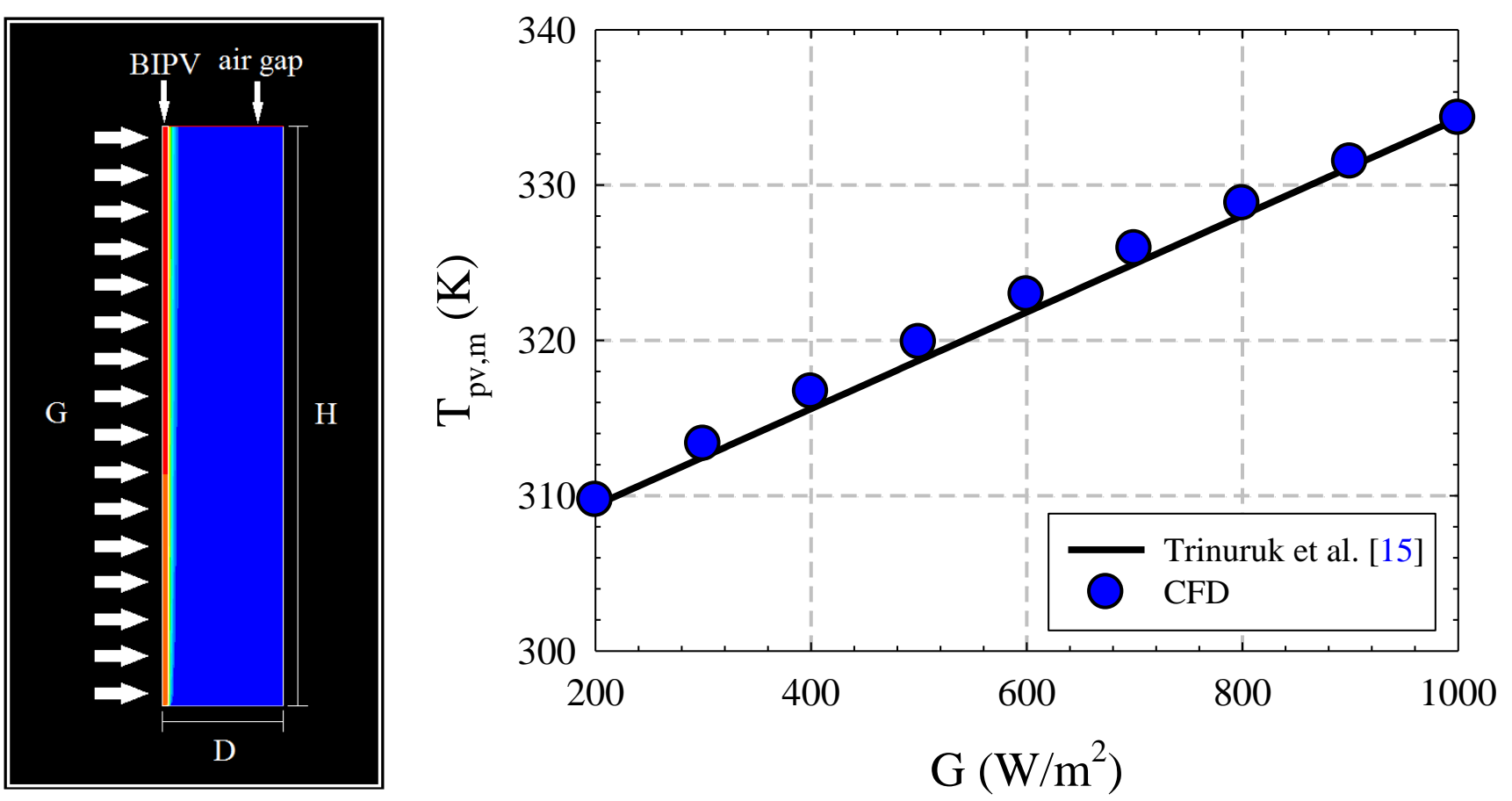

Figure 4. Verification of the CFD results for a particular case of natural convection problem in literature. 


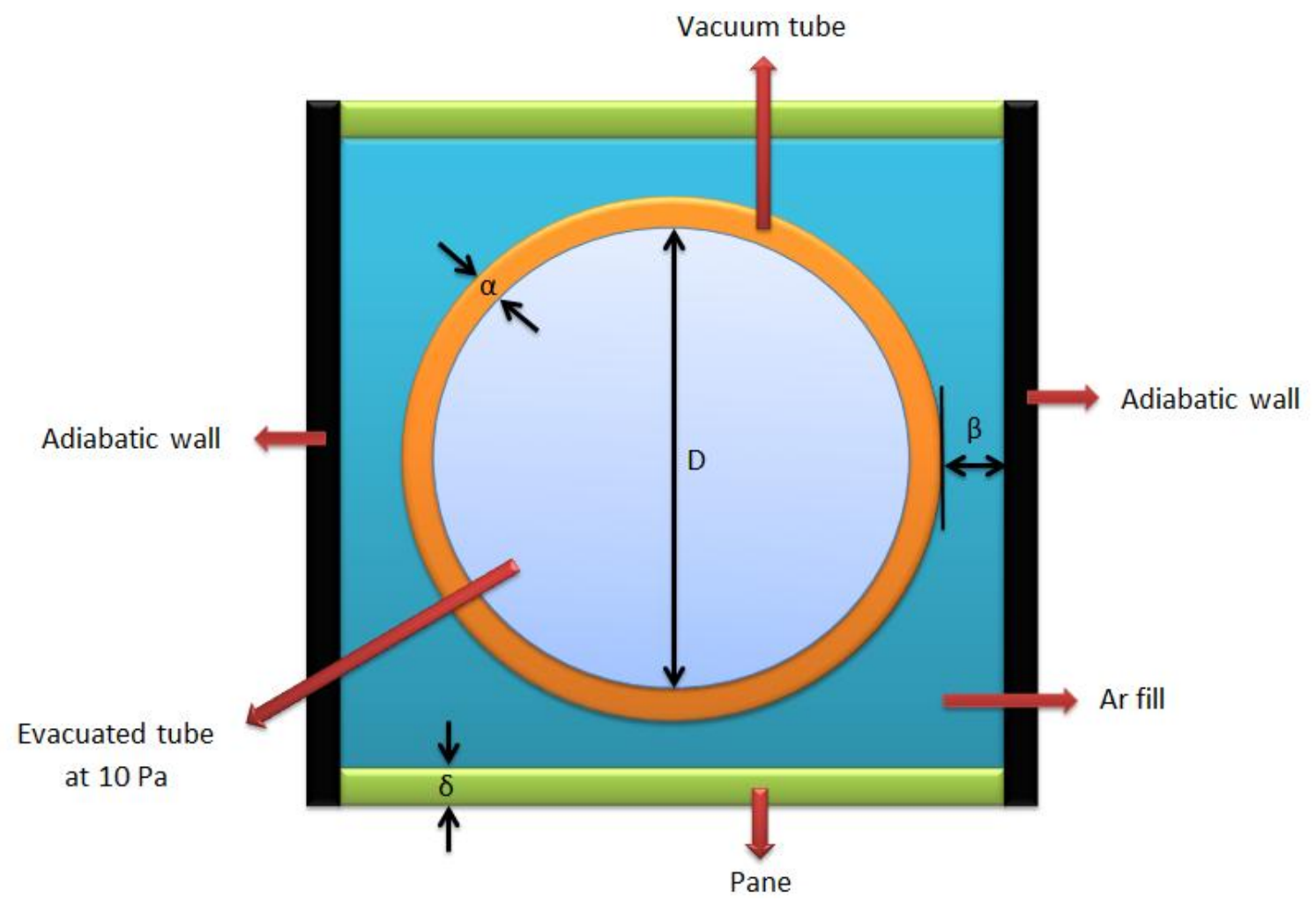

Figure 5. Cross-sectional view of the vacuum tube window. 


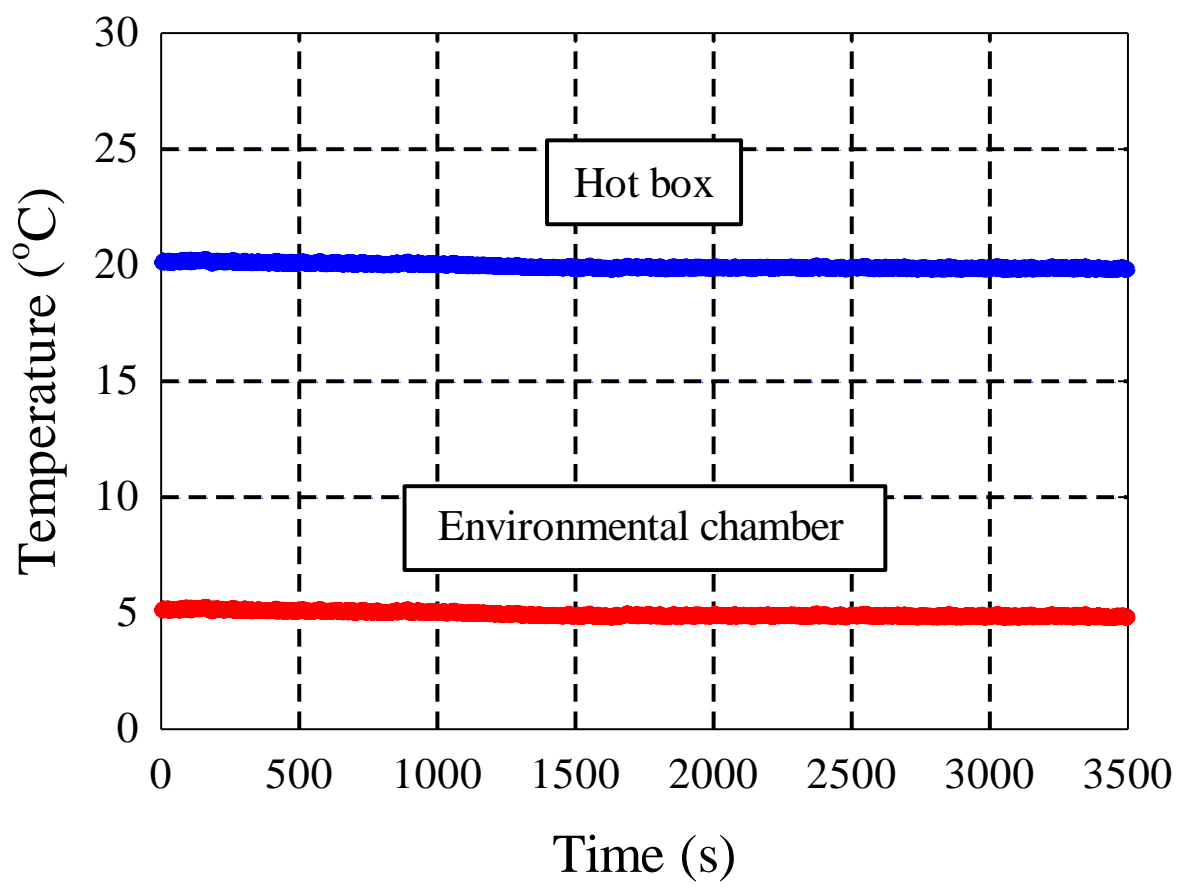

Figure 6. Environmental chamber and hot box temperatures. 

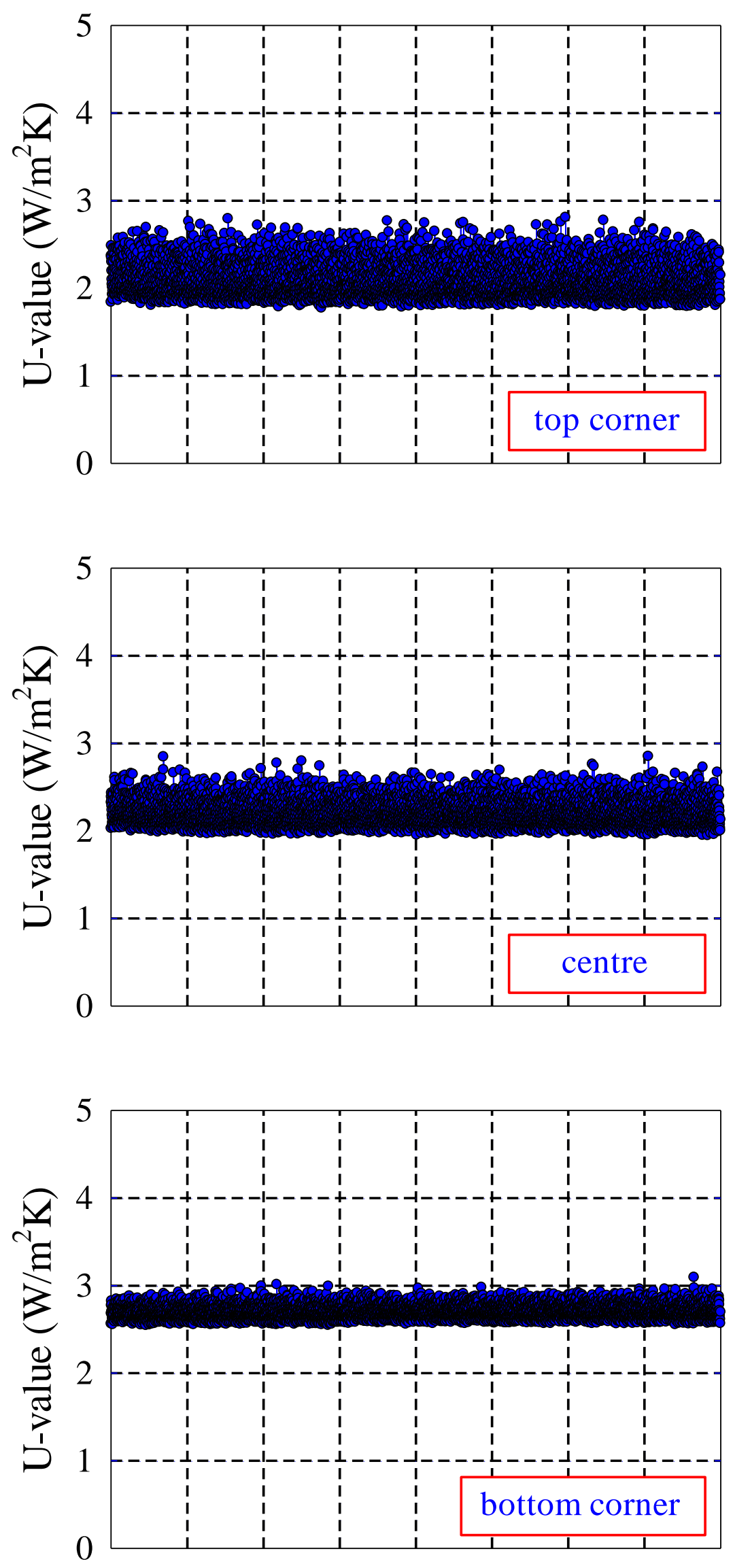

Figure 7. Experimental U-value of the vacuum tube window with a tube diameter of $28 \mathrm{~mm}$. 

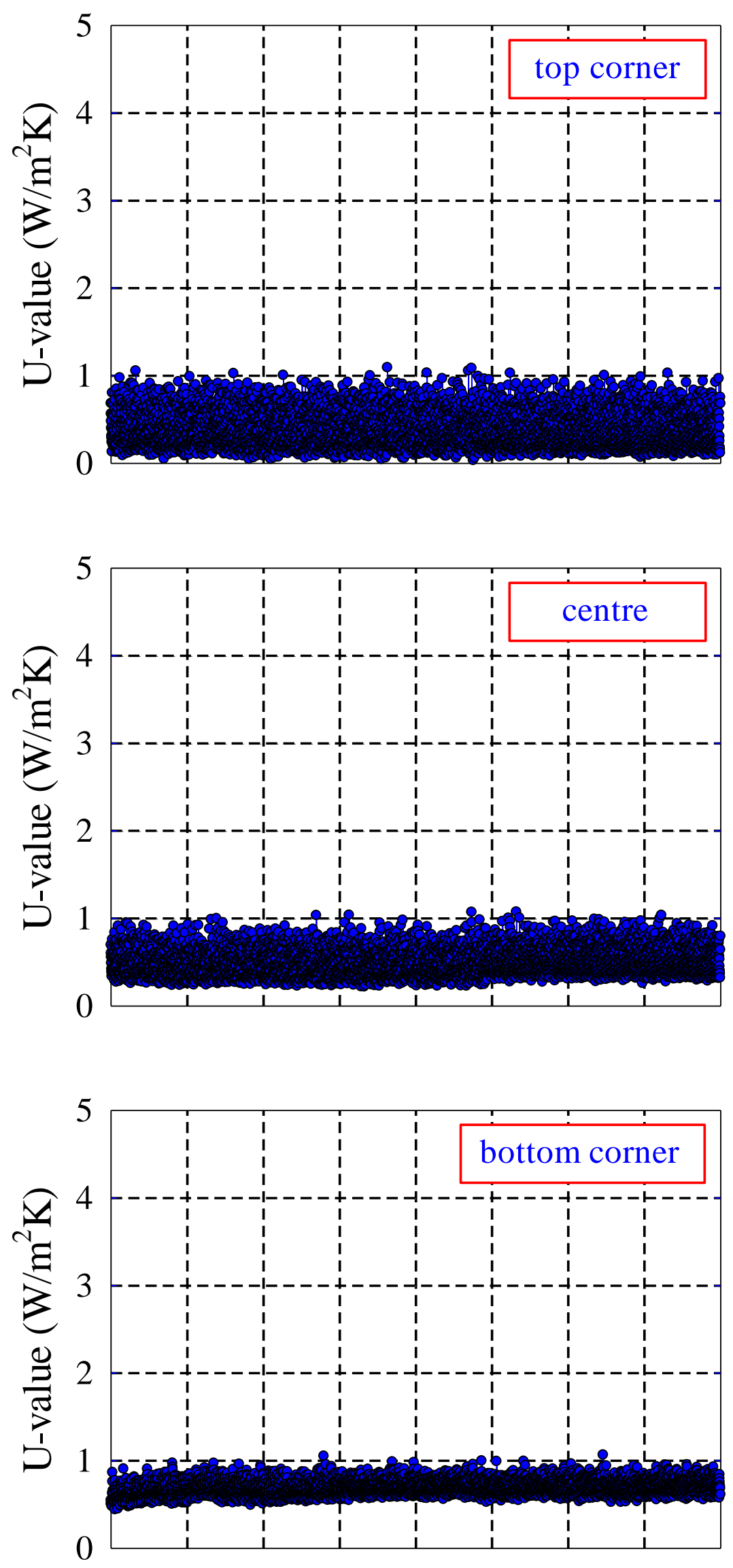

Figure 8. Experimental U-value of the vacuum tube window with a tube diameter of $70 \mathrm{~mm}$. 

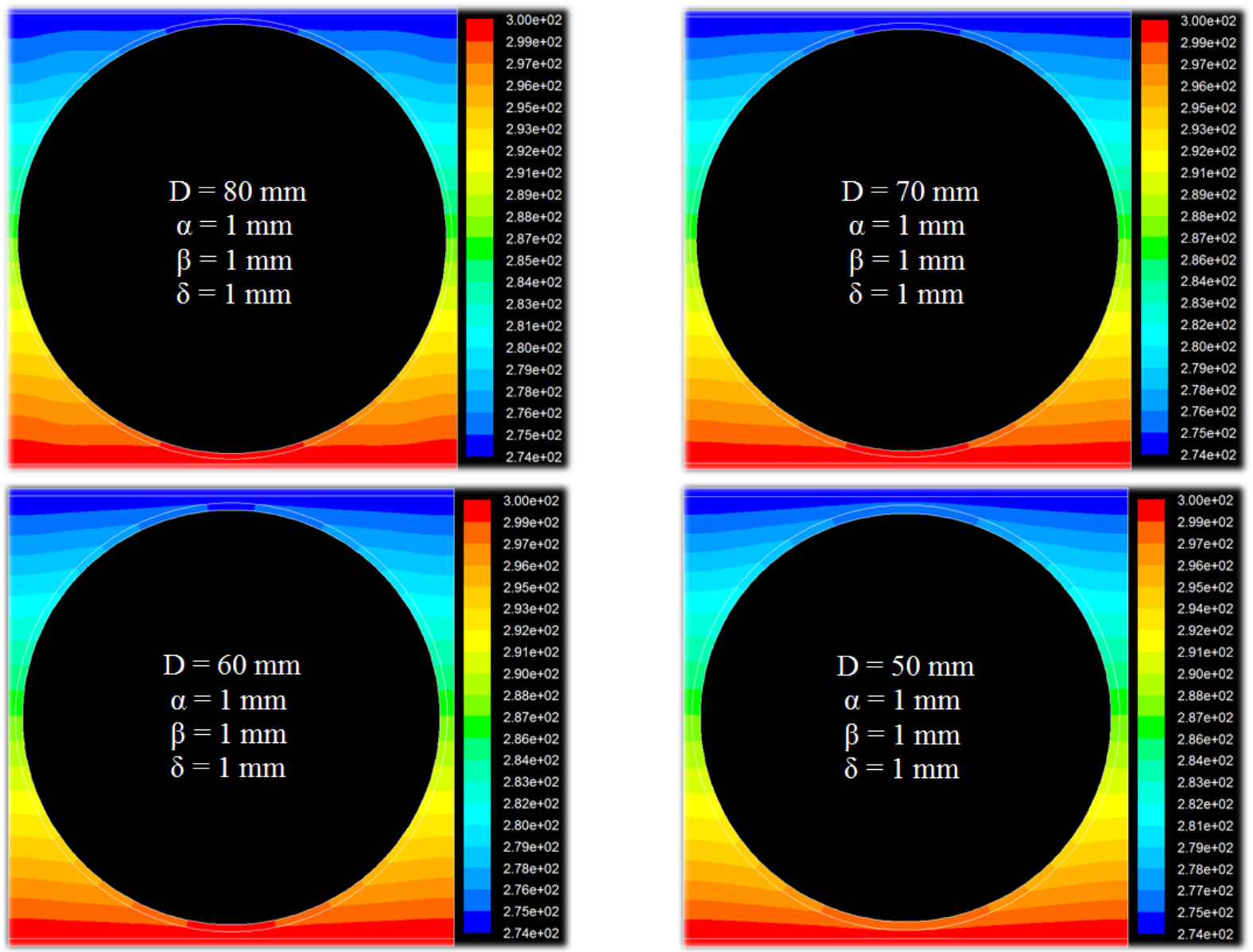

Figure 9. Contours of static temperature for $\mathrm{D}=80,70,60$ and $50 \mathrm{~mm}$, and for $\alpha=\beta=\delta=1$. 

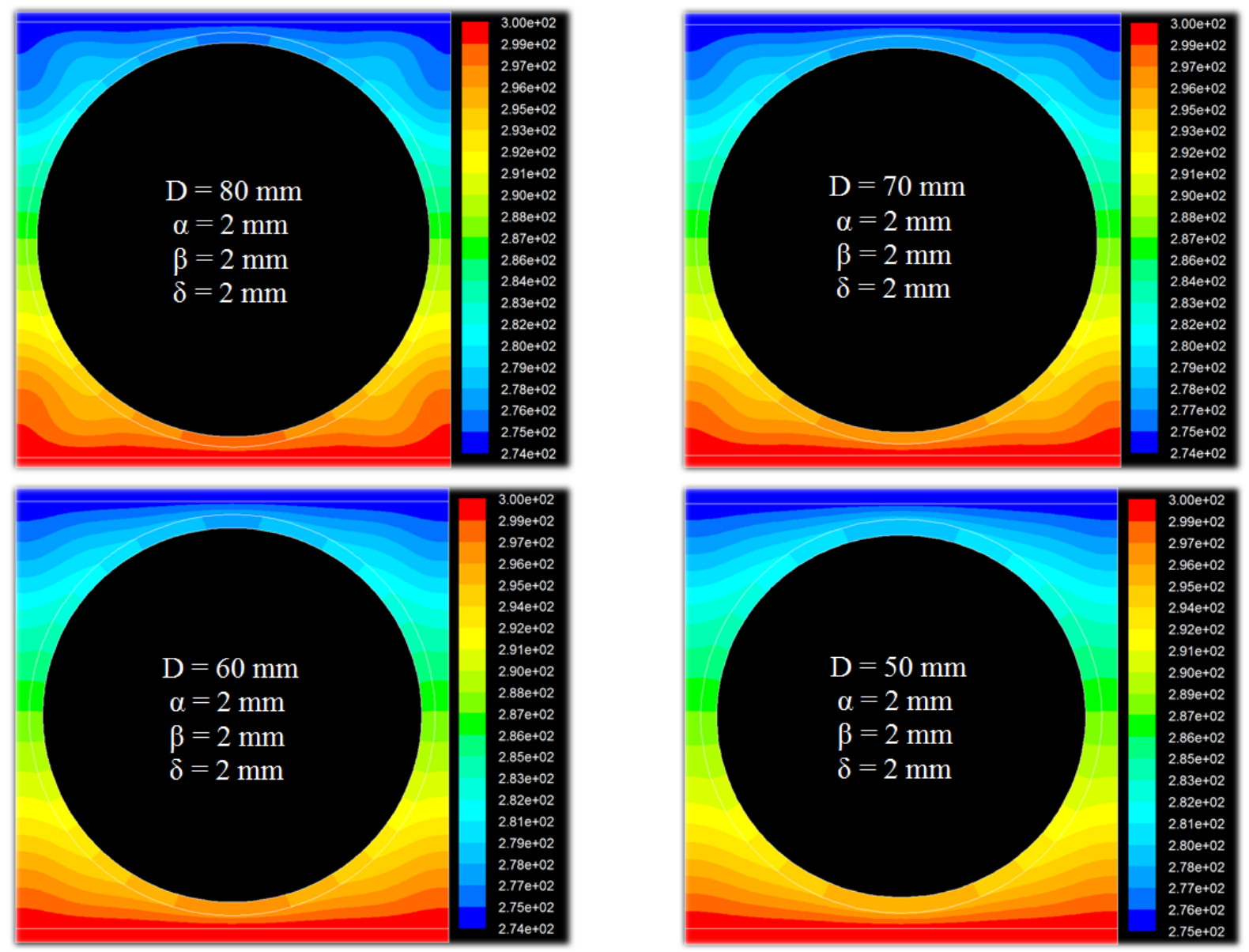

Figure 10. Contours of static temperature for $\mathrm{D}=80,70,60$ and $50 \mathrm{~mm}$, and for $\alpha=\beta=\delta=2$. 

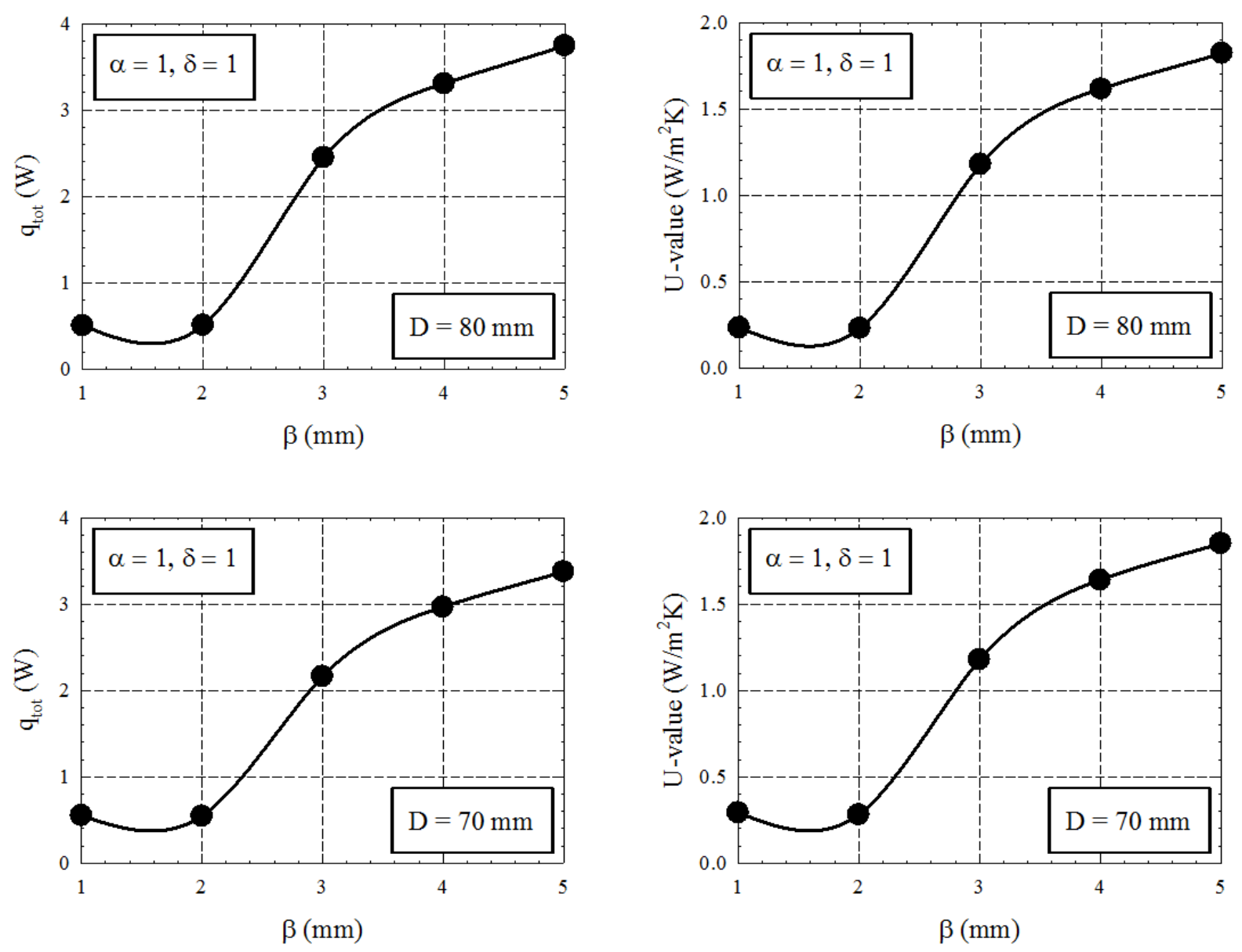

Figure 11. Effect of the thickness of Argon gap between vacuum tubes on heat loss and U-value of the vacuum tube window. 

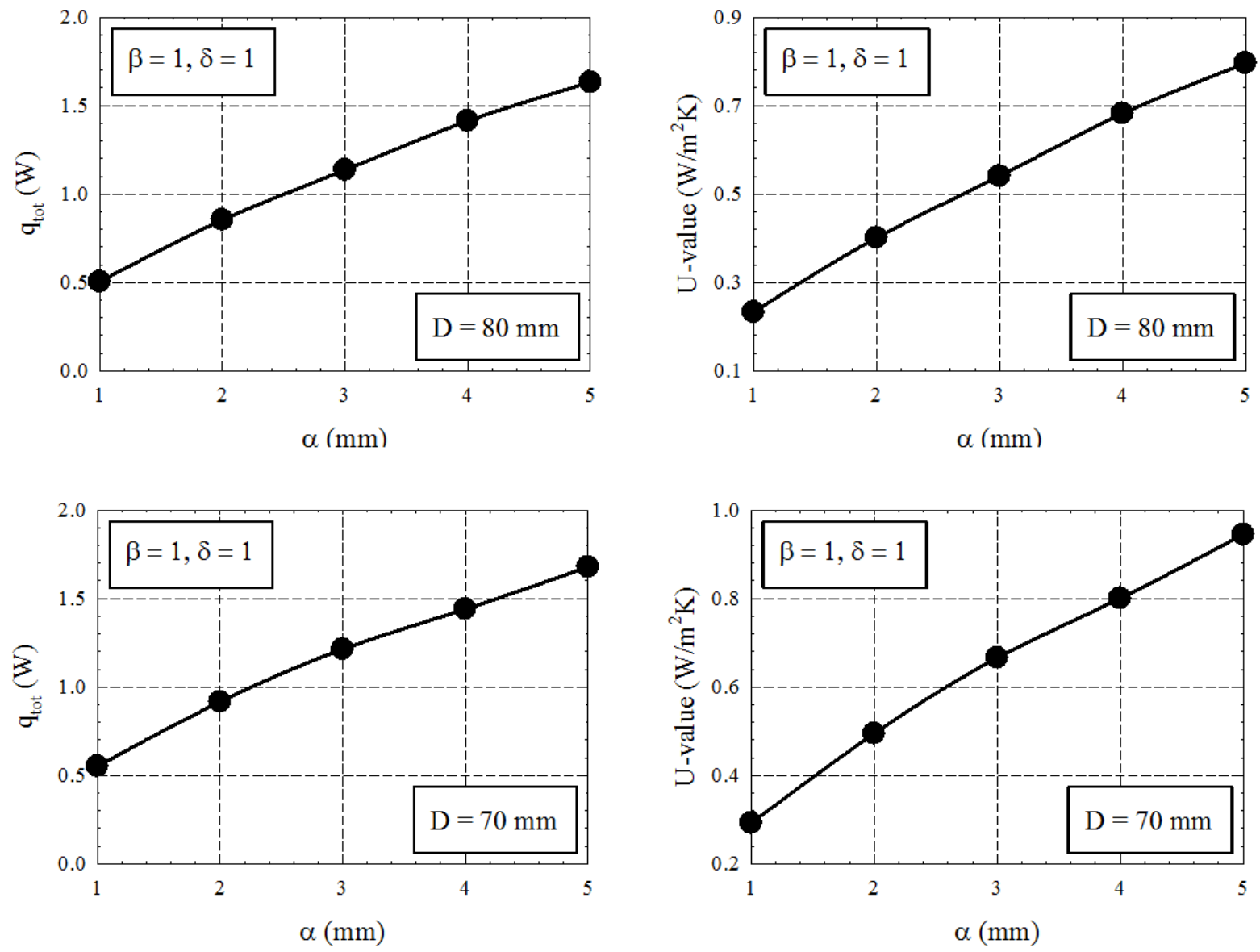

Figure 12. Effect of tube thickness on heat loss and U-value of the vacuum tube window. 

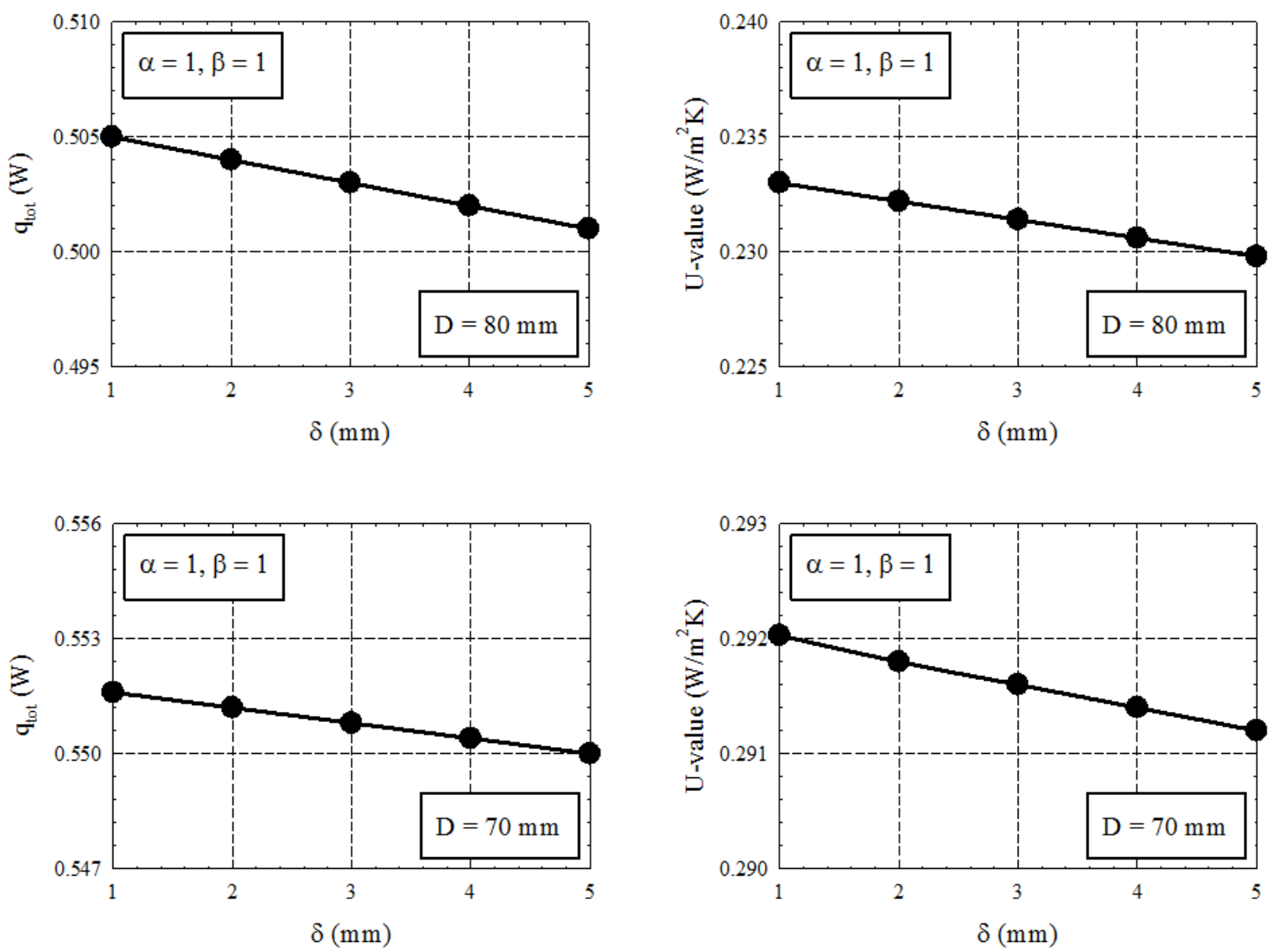

Figure 13. Effect of pane thickness on heat loss and U-value of the vacuum tube window. 

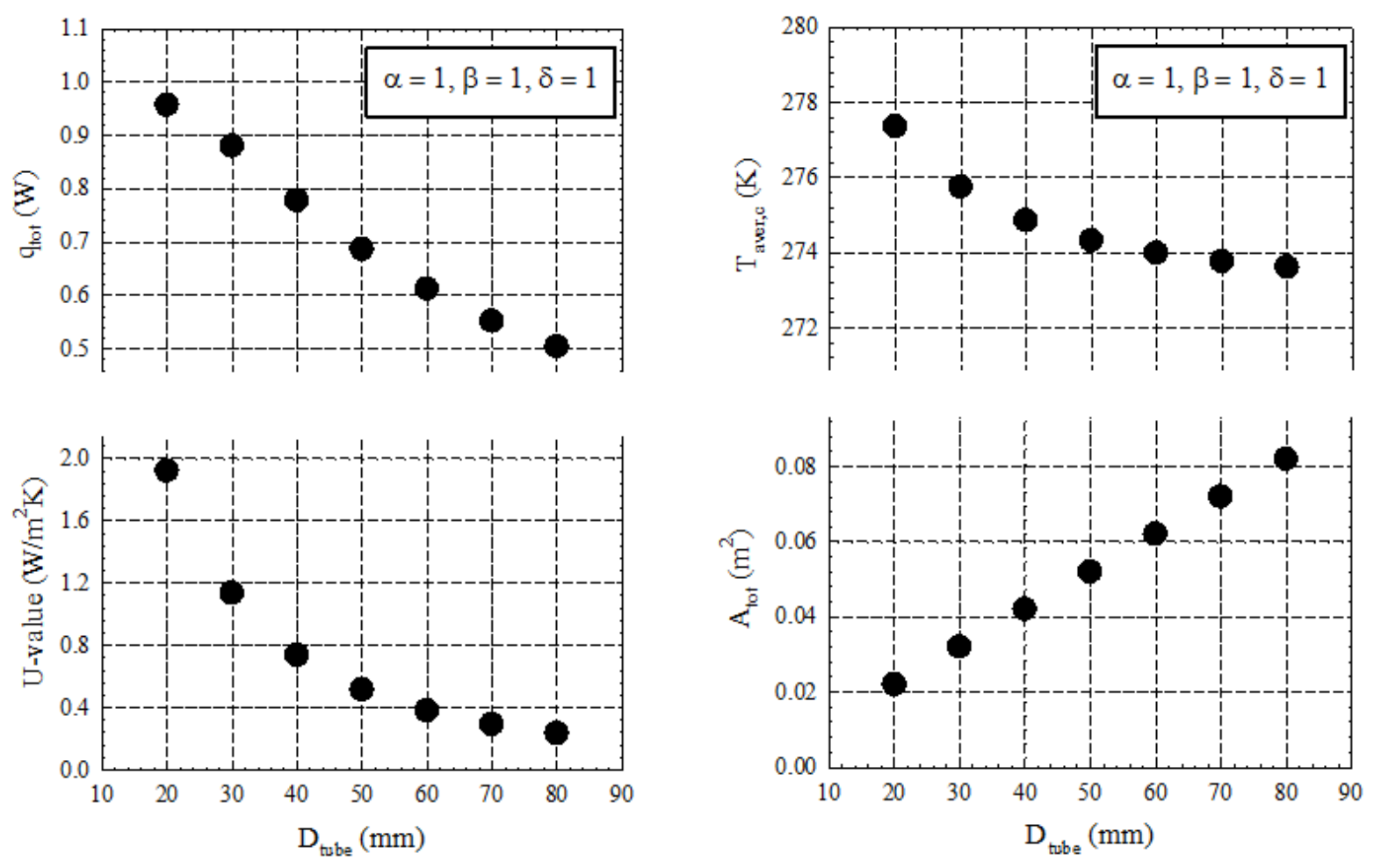

Figure 14. Heat loss, $\mathrm{U}$-value, $\mathrm{T}_{\mathrm{aver}, \mathrm{c}}$ and $\mathrm{A}_{\text {tot }}$ as a function of vacuum tube diameter for $\alpha=1$, $\beta=1$ and $\delta=1 \mathrm{~mm}$. 


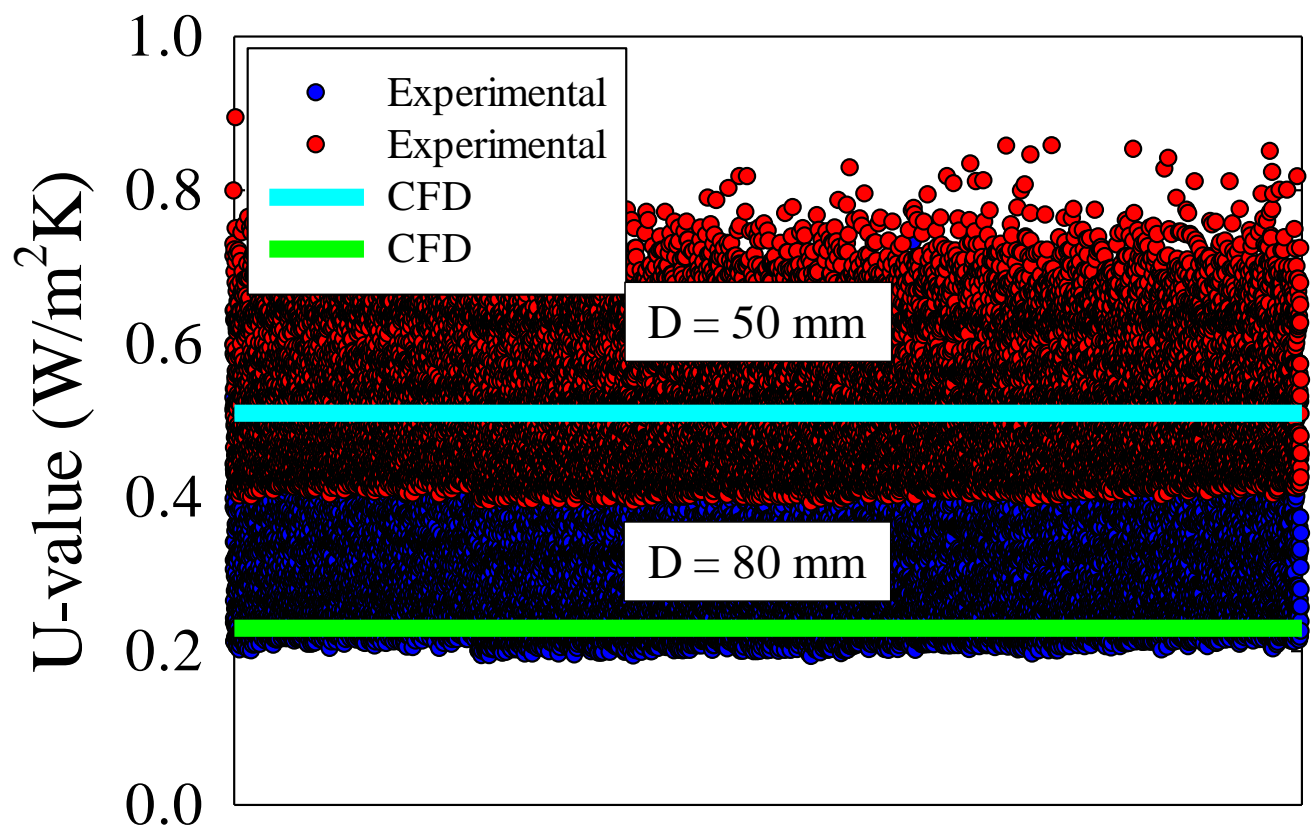

Figure 15. Numerical and experimental U-values for the tube diameters of 50 and $80 \mathrm{~mm}$. 